\title{
Combined autologous bone marrow mononuclear cell and gene therapy as the last resort for patients with critical limb ischemia
}

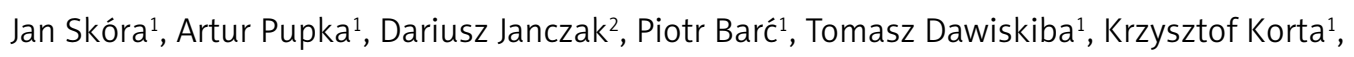
Dagmara Baczyńska ${ }^{3}$, Agnieszka Mastalerz-Migas ${ }^{4}$, Jerzy Garcarek ${ }^{5}$

\begin{abstract}
${ }^{1}$ Department of Vascular, General and Transplantation Surgery, Wroclaw Medical University, Wroclaw, Poland

${ }^{2}$ Department of Clinical Procedures, Wroclaw Medical University, Wroclaw, Poland ${ }^{3}$ Department of Forensic Medicine, Molecular Techniques Unit, Wroclaw Medical University, Wroclaw, Poland

${ }^{4}$ Department of Family Medicine, Wroclaw Medical University, Wroclaw, Poland

${ }^{5}$ Department of General Radiology, Interventional Radiology and Neuroradiology, Wroclaw Medical University, Wroclaw, Poland
\end{abstract}

Submitted: 18 February 2013

Accepted: 17 May 2013

Arch Med Sci 2015; 11, 2: 325-331

DOI: 10.5114 /aoms.2013.39935

Copyright (c) 2015 Termedia \& Banach

\section{Abstract}

Introduction: Our study was designed to investigate the safety and efficacy of combined autologous bone marrow mononuclear cell (MNC) and gene therapy in comparison to conventional drug therapy in patients with critical limb ischemia (CLI).

Material and methods: Thirty-two patients with CLI persisting for 12-48 months (average time 27.5 months) were randomized into 2 groups, each group consisting of 16 patients. In the first group, administration of autologous bone marrow MNC and vascular endothelial growth factor (VEGF) plasmid was performed. The patients from the second group were treated pharmacologically with pentoxifylline. Ankle-brachial index ( $\mathrm{ABI}$ ) was measured and angiography was performed before and finally 3 months after treatment. The pain was evaluated using the Visual Analog Scale (VAS) before and after 3 months. Results: Ankle-brachial index improved significantly from $0.29 \pm 0.21$ to $0.52 \pm 0.23(p<0.001)$ in 12 patients $(75.0 \%) 3$ months after the experimental therapy in group 1. In this group angiography showed the development of collateral vessels. Ischemic ulcers healed completely in 11 patients (68.75\%). In group 2 the $A B I$ did not improve in any patient; moreover the complete healing of skin ulcers was not found in any of the patients of this group. Amputation was performed in $4(25.0 \%)$ patients in group 1 , and in 8 patients (50\%) from group 2.

Conclusions: These data after 3-month follow-up indicate that intramuscular injection of MNC combined with gene therapy in patients with chronic $\mathrm{CLI}$ is safe, and a more feasible and effective method of treatment than the conventional therapy. However, both therapies are limited by the degree of microcirculation damage.

Key words: critical limb ischemia, atherosclerosis obliterans, marrow stem cells, gene therapy.

\section{Introduction}

Critical limb ischemia (CLI) is a term used to define patients with chronic ischemic pain at rest, ulcerations or limb necrosis caused by con-

\author{
Corresponding author: \\ Agnieszka Mastalerz-Migas \\ $\mathrm{MD}, \mathrm{PhD}$ \\ Department of Family \\ Medicine \\ Wroclaw Medical University \\ 1 Syrokomli St \\ 51-141 Wroclaw, Poland \\ Phone: +48 713255126 \\ E-mail: agnieszka.migas@ \\ gmail.com
}


firmed atherosclerotic lesions [1-3]. Critical limb ischemia is estimated to develop in 500 to 1000 people per million per annum [4]. Epidemiological studies show that from $15 \%$ to $20 \%$ of patients with symptomatic atherosclerosis will suffer from $\mathrm{CLI}$ in the future [4-6]. The course of the disease is unfavorable and prognosis is poor [2, 7]. In spite of the technical advances in interventional and surgical revascularization procedures, only $30 \%$ of patients are eligible for limb-preserving arterial surgery [2, 8-10]. The effectiveness of traditional pharmacological therapy is limited and does not cease the progression of the disease. Life-saving limb amputation ("life before limb") is therefore indicated in $40 \%$ of the patients [1, 8-10]. The mortality rate in the course of $\mathrm{CLI}$ is very high (40\%), whereas among patients disqualified from arterial surgery, it reaches $25 \%$ per annum $[6,10]$.

The search for new methods of treatment of $\mathrm{CLI}$ is of primary and basic importance in vascular surgery $[2,3,11,12]$. Recent evidence from clinical studies suggests that neovascularization induced by CD34+ progenitor cells may permit limb salvage even under conditions of complete vessel occlusion $[12,13]$. Also gene therapy with the application of vascular endothelial growth factor (VEGF) plasmid has been conducted in a series of successful studies, on both animals and humans [11, 14-19]. It seems probable that both methods could complement each other in the stimulation of angiogenesis in patients with CLI [20]. The simultaneous use of gene therapy (VEGF) together with progenitor cells may significantly accelerate the formation of collateral vessels in ischemic limbs [20]. Based on literature data and our previous experience with bone marrow mononuclear cells (MNC), we designed a randomized (open-labeled) human clinical trial to compare two therapies for CLI: experimental using combined VEGF gene and autologous MNC, and conventional drug therapy with pentoxifylline [13, 16, 20-25]. Therefore, the primary objective of the study was to assess the safety, feasibility and clinical efficacy of intra-muscular application of autologous bone marrow MNC with plasmid encoding human VEGF165 in patients suffering from CLI. The second main objective of our study was to compare the results of management in patients treated with the above method (the use of CD34+ progenitor cells combined with gene therapy by means of plasmid containing VEGF) with the group treated only with classic drug therapy (pentoxifylline). The secondary objective was to determine whether the application of autologous marrow cells with VEGF165 plasmid is associated with an improvement in arterial blood flow and formation of collateral arteries in patients with CLI not eligible for minimally interventional or surgical revascularization. We made an attempt at introducing the new experimental method of therapeutic angiogenesis in patients with CLI with a hope that positive clinical results of our study could provide a wide group of patients with the possibility of at least partial recovery.

\section{Material and methods}

\section{Patients}

Each year about one hundred patients are hospitalized for CLI in our department. Approximately $70 \%$ of them are successfully treated using surgical or endovascular techniques, which unfortunately is not always possible, and in such situations they usually require a high-level amputation. From the group of patients with lesions in arteries that were not accessible for any surgical or endovascular procedure 32 were enrolled in the study. The patients were divided randomly into two equal groups. Sixteen patients underwent combined autologous bone marrow MNC and gene therapy - group 1 . The remaining 16 patients were treated conventionally with pentoxifylline - group 2.

Patients with proliferative retinopathy, evidence of malignancy, symptomatic coronary artery disease, Leriche's syndrome, terminal renal failure, hepatic dysfunction, history of neoplasm, anemia, leucopenia, thrombocytopenia, diabetes mellitus and other severe diseases were excluded from our study. We excluded diabetic patients to avoid generalization of pyogenic infection from gangrene or ulceration of the affected foot. Clinical characteristics of the study patients are shown in Table I.

Repeated intramuscular injections in the calf of a critically ischemic leg might theoretically trigger infection and septic complications in diabetic patients. The report on this study was approved by the Ethics Committee of Wroclaw Medical University (Approval no. KB-926/2003), and written informed consent was obtained from all patients before enrolment in the study.

\section{Bone marrow collection and preparation}

Bone marrow was harvested by multiple aspiration from iliac crests under general anesthesia using bone a marrow collection kit (Baxter). An average volume of $500 \mathrm{ml}$ was collected. ACD formula A was used to prevent clot formation. After collection, the marrow was filtered with $500 \mu \mathrm{m}$ and $200 \mu \mathrm{m}$ filters included in the kit. The MNC were separated from the harvested marrow with an albumin-primed blood-cell separator (Baxter Fenwall CS 3000 plus) according to the manufacturer's instructions. The final volume of MNC concentrate was adjusted to $80 \mathrm{ml}$ and the end 
product was filtered with a $50 \mu \mathrm{m}$ blood product filter (PALL). The CD34+ cell content was estimated by flow-cytometry according to ISHAGE recommendations [26].

The median final number of prepared MNC was $1.58 \times 10^{9}$ (range from $0.77 \times 10^{9}$ to $3.83 \times 10^{9}$ ) The median number of collected CD34+ cells was $1.7 \times 10^{7}$ (range from $0.12 \times 10^{7}$ to $4.25 \times 10^{7}$ ) . Finally, we obtained $120 \mathrm{ml}$ of the MNC solution.

\section{Preparation of VEGF165 cDNA}

Real time-plymerase chain reaction (RT-PCR) was used for the preparation of VEGF165 CDNA. Total RNA was extracted from endothelium of a vein. $5 \mu$ l of RNA template was provided with oligo(dT) primer using the Super-Script TMIII FirstStrand Synthesis System for RT-PCR (Invitrogen, USA) for the reverse transcriptase (RT) reaction to synthesize cDNA. Afterwards, cDNA was amplified with specific primers for VEGF carrying HindIII and EcoRI restriction sites. This VEGF fragment included a protein leader sequence to permit active secretion. The cDNA sequence is available at GenBank with access number NM_003376. Proof-reading DNA polymerase was used for the PCR reaction (AccuPrime Pfx DNA Polymerase - Invitrogen, USA).

\section{Cloning and preparation of DNA plasmid (phVEGF165)}

We used a eukaryotic expression vector encoding the VEGF165 gene for treatment $[16,17]$. The preparation and purification of the plasmid from phVEGF165-transformed Escherichia coli cultures were performed with the endotoxin-free column method (Qiagen Mega Kit, Qiagen Inc., Valencia, California). The purified plasmid was stored in vials and pooled for quality-control analysis. Aliquots of $2000 \mu \mathrm{g}$ of phVEGF165 were diluted in a sterile saline to the volume of $10 \mathrm{ml}$.

$10 \mathrm{ml}$ of the solution containing $2 \mathrm{mg}$ of VEGF165 plasmid gene was added to the MNC concentrate and incubated for $2 \mathrm{~h}$ before administration.

In RT-PCR stem cell tests the presence of VEGF165 mRNA was detected at a similar level before and after incubation with plasmid. These results prove a low rate of stem cell transfection by naked VEGF plasmid. However, based on our own data and literature data, we expected the occurrence of transfection of connective tissue cells at the place of injection of VEGF plasmid [23, 24]. The expected effect would be an increase in the production of VEGF by ischemic tissue cells, which would significantly improve the settlement of the provided stem cells and their transformation into angioblast cells.

\begin{tabular}{|c|c|c|}
\hline 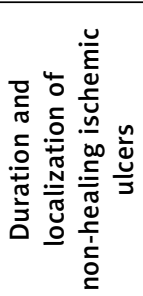 & 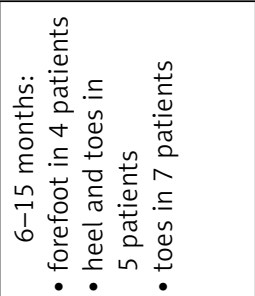 & 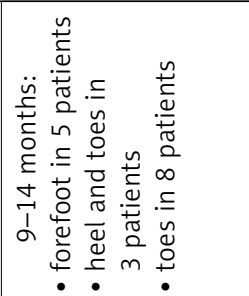 \\
\hline 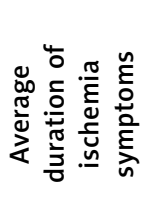 & 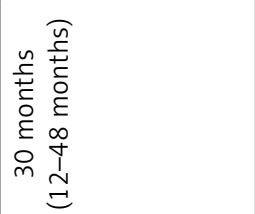 & 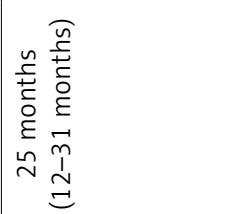 \\
\hline 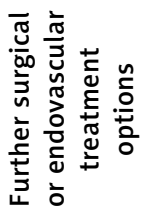 & 운 & ㅇ \\
\hline 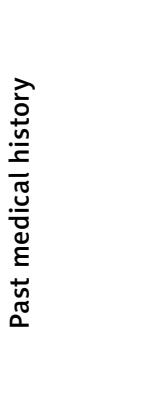 & 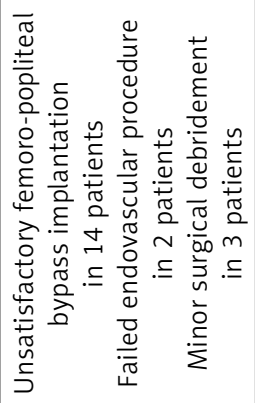 & 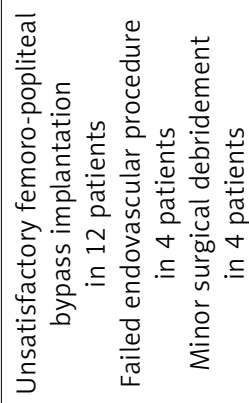 \\
\hline 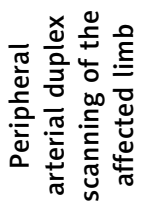 & 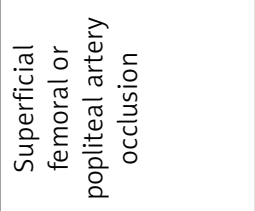 & 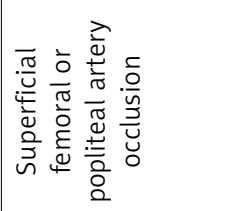 \\
\hline 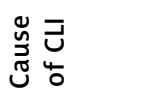 & 운 & 운 \\
\hline 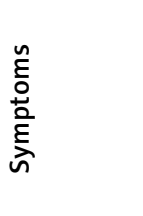 & 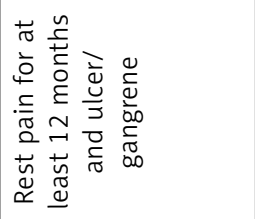 & 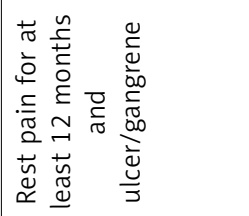 \\
\hline 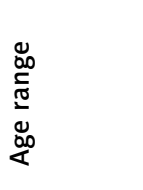 & 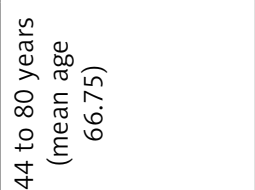 & 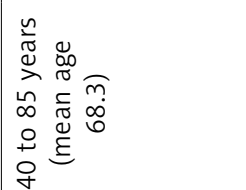 \\
\hline 竞 & 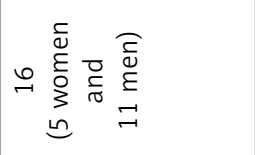 & 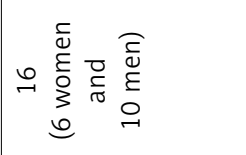 \\
\hline $\begin{array}{l}\frac{0}{3} \\
\frac{0}{3}\end{array}$ & $\rightarrow$ & \\
\hline
\end{tabular}




\section{Combined therapy: application of autologous bone marrow MNC and VEGF plasmid - group 1}

The phVEGF165 and MNC solution was injected intramuscularly into the ischemic lower limb below knee level in patients from group 1. The sites for injection in calf muscles were selected according to data from the literature $[12,13]$. The volume of each injection was $1.5 \mathrm{ml}$ (approximately 80 injections - each $2 \mathrm{~cm}$ deep per session).

\section{Conventional therapy: pentoxifylline administration - group 2}

Patients from this group received pentoxifylline orally $-1,200 \mathrm{mg}$ per day during 3 months of our experimental study.

\section{Clinical assessment}

Heart rate, blood pressure, body temperature, hemoglobin, thrombocytes, leukocytes, C-reactive protein, creatinine, urea, uric acid, gamma GT, lactate dehydrogenase, aspartate aminotransferase as well as alanine aminotransferase were measured at the beginning, 1 day, 1 week and 3 months after the therapy in both groups.

\section{Ankle-brachial index}

Resting ankle-brachial index ( $\mathrm{ABI}$ ) was calculated as the ratio of the lowest pressure from either the posterior or anterior tibial artery divided by the highest brachial systolic pressure, which were obtained 1 week before as well as 1 and 3 months after completion of the MNC injections with phVEGF165 and after the classic drug therapy.

\section{Angiography}

Conventional angiography (arteriography) was performed 1 week before and 3 months after completing the injections. An increase in the number of visible vessels or an increase in the intensity or apparent size of previously visible vessels was considered an improvement. The interpretation of angiograms was performed by a radiologist who was not aware of the treatment status of the patients.

\section{Visual Analog Scale}

The pain was measured by Visual Analog Scale (VAS) the scale ranging from 0 ("no pain") to 10 ("the worst pain"), 1 week before treatment and 12 weeks after administration of autologous bone marrow cells and plasmid of VEGF.

\section{Statistical analysis}

Paired $\chi^{2}$ and Wilcoxon tests were used to compare continuous variables before and after the therapy, and to evaluate the differences between the clusters of measurements taken at individual time points. Value of $p<0.05$ was considered significant.

\section{Results}

\section{Clinical follow-up}

Series of intramuscular injections of VEGF165 gene and MNC were well tolerated by most of the patients. Only two of them reported intense pain during the injections; however, they did not ask to interrupt the procedure. Neither fever, leukocytosis increase, other reactions nor side effects were observed in our patients in the course of the study. There were no significant changes in laboratory parameters during the study.

No major complications were noted. Two patients reported lower limb tenderness at the injection sites lasting for up to $24 \mathrm{~h}$ after the injections. In one case, mild transient limb edema occurred. No patient died or was hospitalized (for other reason than follow-up) during the course of our 90 day observation period. All patients were subject to follow-up for at least 3 months. Four patients treated with the experimental therapy and 8 patients treated with the conventional therapy were subject to limb amputation due to advanced critical ischemia with large ulceration and necrosis accompanied by a severe wound infection. All of them underwent calf-level amputation (Figures 1 and 2). Amputations were performed between the $8^{\text {th }}$ and $12^{\text {th }}$ week of the treatment. In 12 out of 16 patients with hemodynamic improvement (A/B index $>20 \%$ ) from group 1 , the therapy caused rest pain recession, and within the period of 12 weeks after the administration of stem cells with the VEGF gene the total healing of chronic foot ulcerations occurred in 11 of them, while in 1 patient ulcers persisted. In these patients the autologous bone marrow MNC and gene therapy was successful they managed to save their lower limbs from amputation. In the course of the healing process, we performed a surgical debridement of the necrotic tissue. In group 2 treated with pentoxifylline, only one patient reported a decrease in rest pain, and complete healing of skin ulcers and hemodynamic improvement were observed in none of them.

\section{$A B I$ results}

The increase in $A B I$ was observed exclusively in patients treated with the experimental therapy. Among them there were 11 patients with completely healed lower limb ulceration and 1 in whom an improvement in skin ulcer healing was observed. The $A B I$ increased significantly from $0.29 \pm 0.30$ before the treatment to $0.43 \pm 0.43$ ( $p<0.00222$, Wilcoxon test) 4 weeks after stem cell and gene administration. At the end of the 


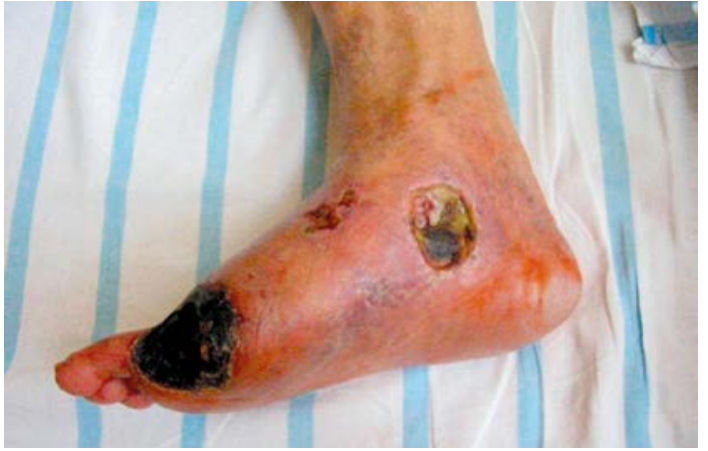

Figure 1. Patient before therapy

study (after 3 months), the index increased significantly ( $p<0.00222$, Wilcoxon test) to $0.52 \pm 0.52$. In 4 cases there was no chance to complete the $A B I$ examination due to lower limb amputation. No improvement in $A B I$ was observed in these patients at 1 month after starting treatment. There was no improvement in the $A B I$ in group 2.

\section{Angiographic studies}

In general, angiography documented the typical findings in advanced atherosclerotic changes in lower limb arteries in all 32 cases. These findings included segmental amputation of the popliteal artery. After the end of the therapy, the formation of new collateral vessels was observed in 12 patients of group 1 (Figures 3 and 4). The comparison of angiograms showed an increase
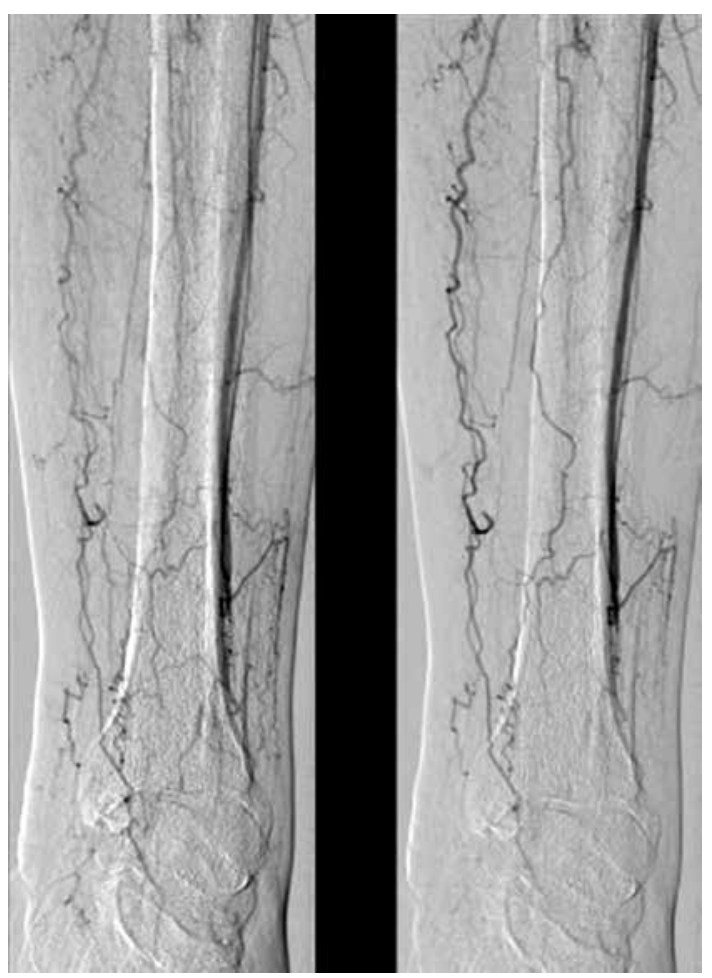

Figure 3. Angiography before therapy

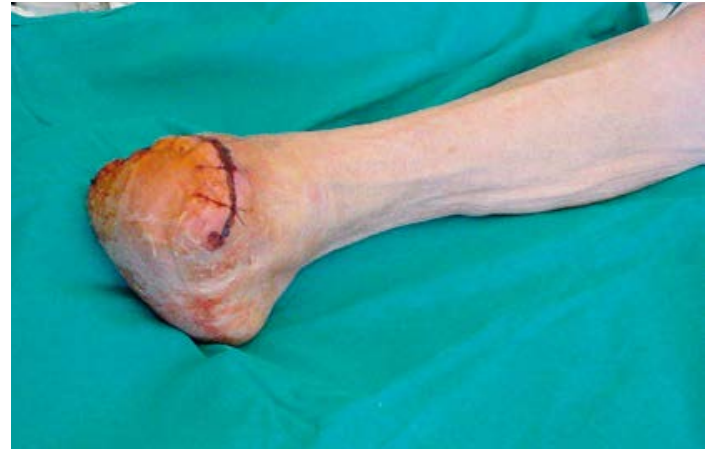

Figure 2. Patient 12 weeks after therapy and minor amputation

in the number, length as well as width of collaterals arising from the superficial femoral artery and popliteal artery. Moreover, in 10 patients who saved their legs, in follow-up angiograms, the lumen of the PTA and tibio-fibular trunk appeared wider and more regular than in the first examination. The number of collaterals arising from the superficial femoral artery did not change, but angiograms showed qualitative evidence of an improvement in the distal flow after the stem cell gene therapy. No such improvement was found in patients of group 2.

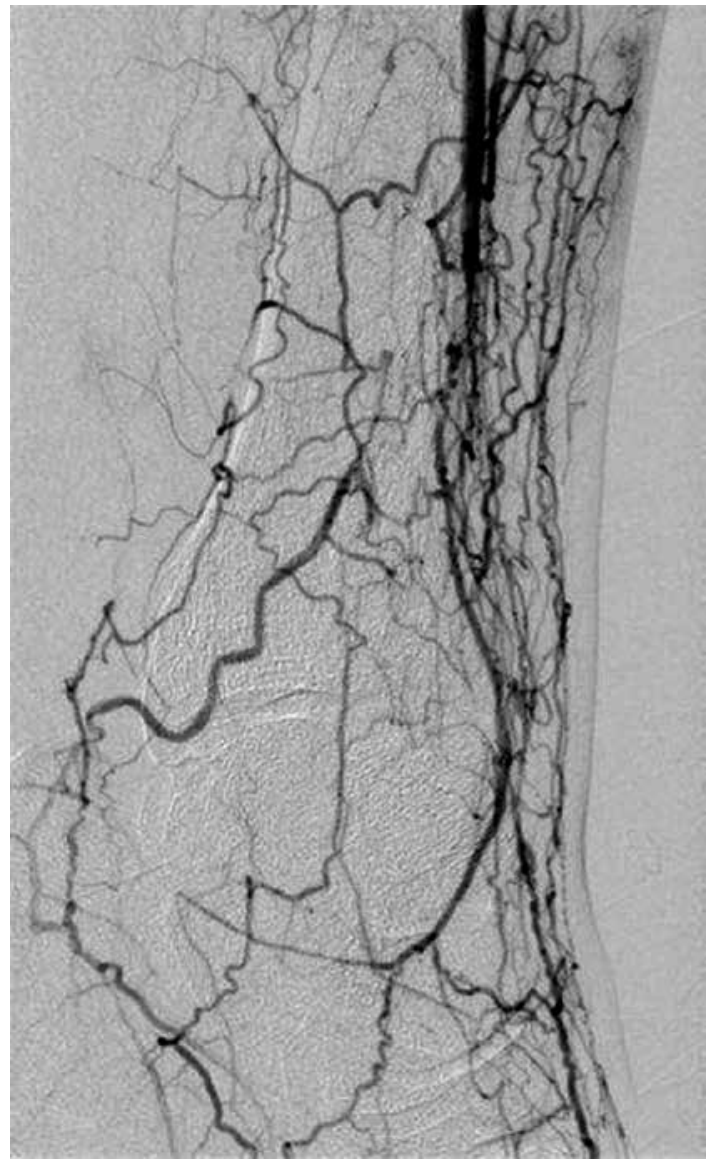

Figure 4. Angiography 12 weeks after therapy 
Table II. Clinical results of therapy

\begin{tabular}{|c|c|c|c|c|c|c|}
\hline \multirow[t]{2}{*}{ Group } & \multirow[t]{2}{*}{$\begin{array}{c}\text { Number of } \\
\text { amputations }\end{array}$} & \multicolumn{3}{|c|}{$\begin{array}{l}\text { Ankle-brachial index in patients without } \\
\text { amputation } \\
\text { (mean } \pm \text { SD) }\end{array}$} & \multirow{2}{*}{$\begin{array}{l}\text { Statistically } \\
\text { significant } \\
\text { decrease } \\
\text { of pain - VAS }\end{array}$} & \multirow[t]{2}{*}{$\begin{array}{l}\text { Angiographic } \\
\text { improvements }\end{array}$} \\
\hline & & $\begin{array}{c}1 \text { week before } \\
\text { therapy }\end{array}$ & $\begin{array}{c}1 \text { month } \\
\text { after therapy }\end{array}$ & $\begin{array}{c}3 \text { months } \\
\text { after therapy }\end{array}$ & & \\
\hline 1 & 4 & $0.29 \pm 0.30$ & $0.43 \pm 0.43$ & $0.52 \pm 0.52$ & 12 patients & 12 patients \\
\hline 2 & 8 & $0.32 \pm 0.28$ & $0.38 \pm 0.30$ & $0.30 \pm 0.29$ & $\begin{array}{c}\text { None of the } \\
\text { patients }\end{array}$ & No improvement \\
\hline
\end{tabular}

\section{Visual Analog Scale}

In group 1 the pain decreased significantly from $6.3 \pm 1.4$ before treatment to $1.2 \pm 1.1$ after 3 months $(p<0.002)$ in 12 patients. The reduction of pain was observed in 11 patients with completely healed ulceration and 1 patient with persistent but healing ulceration of the lower limb. In group 2 the severity of pain was not changed significantly during the study.

The clinical results are summarized in Table II.

\section{Discussion}

The prognosis and quality of life in patients with chronic $\mathrm{CLI}$, rest pain and ischemic ulcers have a downhill course; no pharmacologic treatment has been proved to be effective in these patients [1, 2, 4-6]. Therefore, when lesions in arteries of the affected limb are not accessible for any surgical or endovascular procedure, high-level amputation is usually recommended as the solution of choice. Due to a high amputation rate, it is very important to find and develop alternative treatment strategies in such cases [1-3].

To our knowledge, our study is the first one available in English literature dealing with the application of the combination of the following therapies: autologous bone marrow MNC and gene administration in patients with CLI. Previous trials described treatment with the application of either stem cells or VEGF plasmid separately [12, 13, 21-23].

Our results are not as encouraging as those obtained in the previous studies [21-23]. During the 90-day observation period we achieved a significant clinical improvement in 12 patients with $\mathrm{CLI}$ with non-healing ulcers after combined therapy group 1. In comparison, 8 patients from group 2 also saved their limbs. However, only in the first group did we observe complete healing of skin ulcers and an increase in the $A B I$ : in 11 patients ulcers vanished completely, and in 1 progress in ulcer healing was noticeable. All of them reported a decrease in rest pain, and the $A B I$ increased significantly in all of them. In comparison, only 1 patient from the second group reported a decrease in rest pain, and the healing of ulcers was considerable in none of them. In 4 patients from group 1 and 8 from group 2 with advanced CLI symptoms, amputations were necessary.

From the perspective of patient safety, significant adverse effects were observed in no patient. Apart from some minor discomfort at the injection sites and peripheral edema in 1 case, no other side effects were noted and - in particular during the 90-day follow-up period - there was no evidence of any systemic effects of VEGF in terms of the development of retinopathy or new tumor growth.

Our results also provided preliminary evidence of the potential efficiency of the $\mathrm{MNC}$ /gene therapy in treatment of CLI. In particular, the $A B I$ increased significantly in 12 patients from group 1 . The $A B I$ increased from $0.29 \pm 0.21$ at the baseline to $0.52 \pm 0.2312$ weeks after the injections. To put this in perspective, an increase in $A B I$ of $>0.1$ is considered to indicate a successful surgical or percutaneous intervention [27]. To our knowledge, such an improvement in the $A B I$ has not yet been achieved spontaneously or with medical therapy in patients with CLI, and the results obtained in group 2 confirm this hypothesis [27].

Angiography showed an increased flow in calf arterial vessels in the case of group 1. Angiograms also showed evidence of increased collaterals in all 12 survived limbs but probably underestimated the degree of collateral development as well as the size of the newly formed vessels. The significant reduction of pain after cell/gene therapy was additional evidence of improvement of blood circulation in ischemic limbs. It was randomized, but not double-blind. However, the improvement in clinical symptoms observed in our trial and the hemodynamic and imaging data should be cautiously interpreted as promising, and cannot be attributed to the placebo effect [22, 23, 28-30].

In conclusion, the combined autologous bone marrow mononuclear cell and gene therapy seems to be a very promising form of angiogenesis induction; however, we do not know whether the early positive outcomes will last over time. Yet, it is extremely difficult to state why only 12 patients (75\%) in group 1 benefited from the treatment. The poor results in 4 cases $(25 \%)$ can be probably explained by advanced critical ischemia symptoms with irreversible damage to microcirculation. In these cases therapeutic neoangiogenesis was 
too weak a signal for the restoration of the peripheral vascular bed in critical ischemic muscles. It seems that the MNC gene therapy should be introduced earlier in such cases. Finally, we found that the combined administration of intramuscular MNC and the VEGF gene is a safe and effective method of treatment in our patients with CLI, and should be taken into consideration in patients who have run out of other treatment options.

\section{Conflict of interest}

The authors declare no conflict of interest.

\section{References}

1. Dormandy J, Mahir M, Ascady G, et al. Fate of the patient with chronic leg ischaemia. A review article. J Cardiovasc Surg (Torino) 1989; 30: 50-7.

2. Vogt MT, Wolfson SK, Kuller LH. Lower extremity arterial disease and the aging process: a review. J Clin Epidemiol 1992; 45: 529-42.

3. Aronow WS. Peripheral arterial disease of the lower extremities. Arch Med Sci 2012; 8: 375-88.

4. Creager MA. Medical management of peripheral arterial disease. Cardiol Rev 2001; 9: 238-45.

5. Jelnes R, Gaardsting O, Hougaard Jensen K, Baekgaard N, Tønnesen $\mathrm{KH}$, Schroeder T. Fate in intermittent claudication: outcome and risk factors. Br Med J (Clin Res Ed) 1986; 293: 1137-40.

6. Second European Consensus Document on chronic critical leg ischemia. Eur J Vasc Surg 1992; 6 Suppl A: 1-32.

7. Wozniak K, Sleszycka J, Safianowska A, Wiechno W, Domagala-Kulawik J. Systemic inflammation in peripheral arterial disease with or without coexistent chronic obstructive pulmonary disease: analysis of selected markers. Arch Med Sci 2012; 8: 477-83.

8. Inan B, Aydin U, Ugurlucan M, Aydin C, Teker ME. Surgical treatment of lower limb ischemia in diabetic patients long-term results. Arch Med Sci 2013; 9: 1078-82.

9. Nguyen LL, Lipsitz SR, Bandyk DF, et al. Resource utilization in the treatment of critical limb ischemia: the effect of tissue loss, comorbidities, and graft-related events. J Vasc Surg 2006; 44: 971-5.

10. Eskelinen E, Eskelinen A, Albäck A, Lepäntalo M. Major amputation incidence decreases both in non-diabetic and in diabetic patients in Helsinki. Scand J Surg 2006; 95: 185-9.

11. Iwaguro H, Yamaguchi J, Kalka C, et al. Endothelial progenitor cell vascular endothelial growth factor gene transfer for vascular regeneration. Circulation 2002; 105: 732-8.

12. Tateishi-Yuyama E, Matsubara H, MuroharaT, et al. Therapeutic angiogenesis for patients with limb ischaemia by autologous transplantation of bone-marrow cells: a pilot study and a randomised controlled trial. Lancet 2002; 360: 427-35.

13. Siminiak T, Grygielska B, Jerzykowska O, et al. Autologous bone marrow stem cell transplantation in acute myocardial infarction-report of two cases. Kardiol Pol 2003; 59: 502-10.

14. Shyu KG, Chang H, Wang BW, Kuan P. Intramuscular vascular endothelial growth factor gene therapy in patients with chronic critical leg ischemia. Am J Med 2003; 114: 85-92

15. Kusumanto $\mathrm{YH}$, van Weel V, Mulder NH, et al. Treatment with intramuscular vascular endothelial growth factor gene compared with placebo for patients with diabetes mellitus and critical limb ischemia: a double-blind randomized trial. Hum Gene Ther 2006; 17: 683-91.

16. Hedman M, Hartikainen J, Syvänne M, et al. Safety and feasibility of catheter-based local intracoronary vascular endothelial growth factor gene transfer in the prevention of postangioplasty and in-stent restenosis and in the treatment of chronic myocardial ischemia: phase II results of the Kuopio Angiogenesis Trial (KAT). Circulation 2003; 107: 2677-83.

17. Isner JM, Pieczek A, Schainfeld R, et al. Clinical evidence of angiogenesis after arterial gene transfer of phVEGF165 in patient with ischaemic limb. Lancet 1996; 348: 370-4.

18. Isner JM. Arterial gene transfer of naked DNA for therapeutic angiogenesis: early clinical results. Adv Drug Deliv Rev 1998; 30: 185-97.

19. Stewart DJ, Hilton JD, Arnold JM, et al. Angiogenic gene therapy in patients with nonrevascularizable ischemic heart disease: a phase 2 randomized, controlled trial of AdVEGF(121) (AdVEGF121) versus maximum medical treatment. Gene Ther 2006; 13: 1503-11.

20. Yang J, Zhou W, Zheng W, et al. Effects of myocardial transplantation of marrow mesenchymal stem cells transfected with vascular endothelial growth factor for the improvement of heart function and angiogenesis after myocardial infarction. Cardiology 2007; 107: 17-29.

21. Kalka C, Masuda H, Takahashi T, et al. Transplantation of ex vivo expanded endothelial progenitor cells for therapeutic neovascularization. Proc Natl Acad Sci U S A 2000; 97: 3422-7.

22. Yamamoto K, Kondo T, Suzuki S, et al. Molecular evaluation of endothelial progenitor cells in patients with ischemic limbs: therapeutic effect by stem cell transplantation. Arterioscler Thromb Vasc Biol 2004; 24: e192-6.

23. Skóra J, Sadakierska-Chudy A, Pupka A, et al. Application of VEGF165 plasmid in treatment of critical lower limb ischemia. Pol Merkur Lekarski 2006; 20: 655-9.

24. Sadakierska-Chudy A, Baczyńska D, Skóra J, Gębarowska E, Pupka A, Dobosz T. Transfection efficiency and cytotoxicity of transfection reagents in human umbilical vein endothelial cells. Adv Clin Exp Med 2008; 17: 625-34.

25. Mughal NA, Russell DA, Ponnambalam S, Homer-Vanniasinkam $\mathrm{S}$. Gene therapy in the treatment of peripheral arterial disease. Br J Surg 2012; 99: 6-15.

26. Sutherland DR, Anderson L, Keeney M, Nayar R, ChinYee I. The ISHAGE guidelines for CD34+ cell determination by flow cytometry. International Society of Hematotherapy and Graft Engineering. J Hematother 1996; 5: 213-26.

27. Muona K, Mäkinen K, Hedman M, Manninen H, Ylä-Herttuala S. 10-year safety follow-up in patients with local VEGF gene transfer to ischemic lower limb. Gene Ther 2012; 19: 392-5.

28. Tio RA, Tan ES, Jessurun GA, et al. PET for evaluation of differential myocardial perfusion dynamics after VEGF gene therapy and laser therapy in end-stage coronary artery disease. J Nucl Med 2004; 45: 1437-43.

29. Choksy S, Pockley AG, Wajeh YE, Chan P. VEGF and VEGF receptor expression in human chronic critical limb ischaemia. Eur J Vasc Endovasc Surg 2004; 28: 660-9.

30. Rutherford RB, Becker GJ. Standards for evaluating and reporting the results of surgical and percutaneous therapy for peripheral arterial disease. Radiology 1991; 181: 277-81. 